\title{
Applying an ensemble Kalman filter to the assimilation of AERONET observations in a global aerosol transport model
}

\author{
N. A. J. Schutgens ${ }^{1}$, T. Miyoshi ${ }^{2, *}$, T. Takemura ${ }^{3}$, and T. Nakajima ${ }^{1}$ \\ ${ }^{1}$ Center for Climate System Research (CCSR), University of Tokyo, Kashiwanoha, Japan \\ ${ }^{2}$ Japanese Meteorological Agency (JMA), Tokyo, Japan \\ ${ }^{3}$ Research Institute for Applied Mechanics (RIAM), Kyushu University, Fukuoka, Japan \\ *now at: Department of Atmospheric and Oceanic Science (AOSC), College Park, Maryland, USA
}

Received: 10 August 2009 - Published in Atmos. Chem. Phys. Discuss.: 11 November 2009

Revised: 9 February 2010 - Accepted: 2 March 2010 - Published: 12 March 2010

\begin{abstract}
We present a global aerosol assimilation system based on an Ensemble Kalman filter, which we believe leads to a significant improvement in aerosol fields. The ensemble allows realistic, spatially and temporally variable model covariances (unlike other assimilation schemes). As the analyzed variables are mixing ratios (prognostic variables of the aerosol transport model), there is no need for the extra assumptions required by previous assimilation schemes analyzing aerosol optical thickness (AOT).

We describe the implementation of this assimilation system and in particular the construction of the ensemble. This ensemble should represent our estimate of current model uncertainties. Consequently, we construct the ensemble around randomly modified emission scenarios.

The system is tested with AERONET observations of AOT and Angström exponent (AE). Particular care is taken in prescribing the observational errors. The assimilated fields (AOT and AE) are validated through independent AERONET, SKYNET and MODIS Aqua observations. We show that, in general, assimilation of AOT observations leads to improved modelling of global AOT, while assimilation of AE only improves modelling when the AOT is high.
\end{abstract}

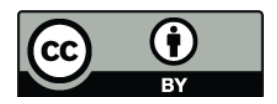

Correspondence to: N. A. J. Schutgens (schutgen@ccsr.u-tokyo.ac.jp)

\section{Introduction}

Although climate change is driven by greenhouse gases, aerosols are actually considered the major unknown contributor to the atmospheric radiative balance. This is a consequence of both poorly constrained global aerosol distributions, as well as poorly understood cloud-aerosol interactions. AeroCom (Textor et al., 2006), a major effort to compare aerosol global models, found that the difference between models can be larger than the difference between a model and the observations. In particular, it has become clear that aerosol modelling suffers from both poorly known boundary conditions (emission scenarios) and poorly known parametrisations for various aerosol processes (Textor et al., 2007). While aerosol models have rapidly increased in complexity and continue to be be further developed (Ghan and Schwartz, 2007), there is an immediate need for dealing with various aerosol model errors, due to an increased demand for reliable global aerosol fields.

Aside from further improvements in aerosol modelling, aerosol simulation may benefit greatly from successful assimilation of observations. First, it would improve aerosol predictions, second it would provide a consistent framework for assessing various model error sources. In principle, aerosol assimilation allows one to treat various parameters in a model as free parameters and provides a technique to fit those free parameters to available observations.

In an assimilation system, model results and observations are combined to arrive at a weighted average which is closer to the truth than the model results by themselves. Successful assimilation requires a solution to two fundamental issues: 1) how to determine the weighting factors; 2 ) how to spread the

Published by Copernicus Publications on behalf of the European Geosciences Union. 
information from localized observations into the model grid. Both of these issues may be addressed through the model prediction error covariance, a matrix that descibes the covariances among model variables due to variations in model parameters. Assimilation systems often differ fundamentally in how they construct this covariant matrix. But once it has been constructed, comparison of the model prediction error covariance to the errors in the assimilated observations allows the solution of the above-mentioned issues.

Aerosol assimilation is a relatively new field of research, owing to aerosol modelling itself being new. Collins et al. (2001) attempted Optimal Interpolation (OI) of daily AVHRR $^{1}$ AOT in a regional model, and $\mathrm{Yu}$ et al. (2003) similarly used MODIS ${ }^{2}$ AOT for a global model. Using the 3D-var formalism, Henzing (2005) assimilated ATSR ${ }^{3}$ AOT. Generoso et al. (2007) used POLDER ${ }^{4}$ observations of AOT and fine mode AOT in a 3D-var scheme. In these studies, AOT was always the analysed variable, and various assumptions were necessary to translate the analysed AOT into profiles of several species of aerosol for further model simulation. When Tombette et al. (2009) assimilated surface observations of $\mathrm{PM}_{10}$ using $\mathrm{OI}$, they faced a similar problem. In addition, in both OI and 3D-var techniques, the model error covariant structure has to be assumed a-priori and it usually does not vary in space or time. Possibly these limitations explain why those studies only showed a mild improvement in aerosol modelling.

Therefore, some research groups have focussed on an isolated aerosol species with dedicated observations. Zhang et al. (2008) employed a 3D-var system for MODIS AOT to improve sea salt modelling in a global model. Niu et al. (2008) and Lin et al. (2008) analysed desert dust in a regional model, assimilating either surface visibility and satellite dust loading measurements or $\mathrm{PM}_{10}$ observations, to improve dust forecasting in China. Niu et al. (2008) employed a 3D-var system while Lin et al. (2008) chose an ensemble Kalman filter (EnKF). Yumimoto et al. (2008) used LIDAR extinction by desert dust (identified from its depolarization ratio) to improve dust storms with a 4D-var scheme. In general, these studies showed improvement in the modelling of the aerosol field.

At the European Centre for Medium-Range Weather Forecasting (ECMWF), a 4D-var ystem for global aerosol assimilation has been developed by Benedetti et al. (2009), using MODIS observations. The potential of space-borne LIDAR observations of aerosols from CALIPSO was shown by Sekiyama et al. (2010). For an alternative take on combining model results and observations, see Dubovik et al. (2008) who attempted to fit MODIS observations to transport calculations with global emission as free parameters.

\footnotetext{
${ }^{1}$ Advanced Very High Resolution Radiometer

${ }^{2}$ Moderate Resolution Imaging Spectroradiometer

${ }^{3}$ Along Track Scanning Radiometer

${ }^{4}$ POLarization and Directionality of Earth's Reflectances
}

In data assimilation, Ensemble Kalman filters are a new development (Evensen, 1994). In an ensemble Kalman filter, an ensemble of model simulations is used to represent the model prediction error covariance. This allows for realistic, spatially and temporally varying covariances to propagate the observed information in the model grid. Although $4 \mathrm{D}$-var schemes can in principle also represent spatially and temporally varying model covariances, CPU and memory restraints make this rather impractical for global models . Also, development of a 4D-var system is much more complicated than an EnKF as the latter is essentially independent of the model that is used. For a further comparison of 4D-var and EnKF, we refer to Kalnay et al. (2007). Various flavours of EnKF have been developed, e.g. Houtekamer and Mitchell (1998) used a double ensemble to improve statistical representation and Whitaker and Hamill (2002) introduced the ensemble square root filter which allows easier treatment of the observations.

In this paper, we will introduce a new assimilation system for global aerosol simulations, based on the Spectral Radiation-Transport Model for Aerosol Species (SPRINTARS) (Takemura et al., 2000, 2002, 2005) and the Local Ensemble Transform Kalman filter (LETKF) (Hunt et al., 2007; Miyoshi and Yamane, 2007; Szunyogh et al., 2008). This system will assimilate AERONET observations of AOT and AE. The resulting global aerosol fields (again AOT and AE) will be validated with independent observations from AERONET, SKYNET and MODIS Aqua. In a future paper, we discuss several sensitivity studies that were performed for the assimilation system, show its robustness and determine optimal values for various numerical parameters.

In Sect. 2, we present a quick overview of the Kalman filter and describe in detail the approach we have taken to apply an ensemble Kalman filter to global aerosol modelling. In Sect. 3, we briefly introduce the global aerosol model SPRINTARS and the modifications we introduced for the current paper. Since good observations are essential to reliable assimilation, Sect. 4 discusses the quality-assured level 2 AERONET data and discusses how we arrived at our observational error statistics. The results of the assimilation will be compared to both the standard simulation and independent observations in Sect. 5. A summary of our work can be found in Sect. 6.

\section{LETKF: ensemble Kalman filter}

\subsection{The Kalman equation}

In any Kalman filter, the essential equation to solve is the Kalman equation (Rodgers, 2000) which relates an analysed state $\mathbf{x}_{a}$ to the forecast state $\mathbf{x}_{f}$ as

$$
\mathbf{x}_{a}=\mathbf{x}_{f}+\mathbf{P}_{a} \cdot \mathbf{H}^{T} \cdot \mathbf{R}^{-1} \cdot\left(\mathbf{y}-\mathbf{H} \cdot \mathbf{x}_{f}\right) .
$$


Here $\mathbf{x}$ is a vector containing the state of the model (in our case, aerosol mixing ratios for fine and coarse aerosol at all grid locations, including all vertical levels). The forecast state is updated (to the analysis) by considering the innovation, the difference between actual $(\mathbf{y})$ and simulated values $\left(\mathbf{H x}_{f}\right)$ of selected observables. In this paper, $\mathbf{y}$ will be a vector of observed AOT and AE at various locations. The observation operator $\mathbf{H}$ transforms the forecast state vector into simulated observations. Finally, the innovation is multiplied with the so-called Kalman gain which contains the model prediction error covariance $\mathbf{P}$, the observation operator and the observational error covariance $\mathbf{R}$, all of which are matrices.

The only unknown variable in Eq. (1), apart from $\mathbf{x}_{a}$, is the analysis model prediction error covariance $\mathbf{P}_{a}$. It must either be assumed or it can be found by solving

$\mathbf{P}_{a}=\left(\mathbf{I}+\mathbf{P}_{f} \cdot \mathbf{H}^{T} \cdot \mathbf{R}^{-1} \cdot \mathbf{H}\right)^{-1} \cdot \mathbf{P}_{f}$,

where $\mathbf{I}$ is the identity matrix and $\mathbf{P}_{f}=\left\langle\mathbf{x}_{f} \mathbf{x}_{f}\right\rangle$ the forecast model prediction error covariance. The latter can, in principle, be obtained from model calculations (more on this later).

It can be shown (e.g. Bouttier and Courtier, 1999; Rodgers, 2000) that solving these equations is equal to minimizing the following cost function

$$
\begin{aligned}
\Psi\left(\mathbf{x}_{a}\right)= & \left(\mathbf{x}_{f}-\mathbf{x}_{a}\right)^{T} \cdot \mathbf{P}_{f}^{-1} \cdot\left(\mathbf{x}_{f}-\mathbf{x}_{a}\right)+ \\
& \left(\mathbf{y}-\mathbf{H} \cdot \mathbf{x}_{a}\right)^{T} \cdot \mathbf{R}^{-1} \cdot\left(\mathbf{y}-\mathbf{H} \cdot \mathbf{x}_{a}\right),
\end{aligned}
$$

which minimizes the "distance" of $\mathbf{x}_{a}$ to both the forecast $\mathbf{x}_{f}$ and the observations, while taken the error estimates in both forecast and observations into account.

The model prediction error covariance is assumed a-priori (Bouttier and Courtier, 1999) in many implementations of the Kalman filter (notably optimal interpolation and 3D-var, but usually also in $4 \mathrm{D}$-var). Often, observations will be used to guide its shape, but there will be no causal relationship between the simulated $\mathbf{x}_{f}$ and the assumed $\mathbf{P}_{f}$. For optimal interpolation and 3D-var, this is due to limitations in the assimilation approach. For 4D-var, this is due to computer resource restraints. If the state vector has $n$ elements, than the covariance matrix has $n^{2}$ elements that all have to be propagated forward in time. In the ensemble Kalman filter this problem is removed by calculating $\mathbf{P}_{f}$ from an ensemble of model calculations at the moment of assimilation. Since $P$ will evolve as the ensemble $\mathbf{x}_{f}$ evolves, the ensemble Kalman filter can represent flow-dependent covariance information. The drawback is that this covariance is noisy as it is an average over a finite size ensemble.

\subsection{Local ensemble transform Kalman filter}

The LETKF is a recent development of the ensemble Kalman filter (Hunt et al., 2007; Miyoshi and Yamane, 2007; Szunyogh et al., 2008), aimed at efficient parallel treatment of the assimilation algorithm. In the LETKF the assimilation is performed while considering only a local subgrid of the full grid. This is possible since spatial correlations in the aerosol field usually extend over no more than a few hundreds of kilometers. Any observations more than, say, $1000 \mathrm{~km}$ away from a grid-point are unlikely to contain useful information for the assimilation in that grid-point. As a consequence, the assimilation can be very effectively parallelized, with different processors calculating the analysed state vector of different regions of the full grid.

In any ensemble Kalman filter, there are a number of numerical parameters that require (some) tuning for the filter to work optimally. For LETKF, these are (roughly from most to least important): ensemble size $n_{\mathrm{e}}$, local patch size $l_{\mathrm{p}}$ and horizontal localization factor $l_{\mathrm{h}}$ (together $l_{\mathrm{p}}$ and $l_{\mathrm{h}}$ define the maximum range, in grid-points, at which observations still influence the assimilation) and inflation parameter $g$ (a multiplier to increase the ensemble spread to mitigate the negative influence of a limited ensemble size). More detailed information can be found in aforementioned publications or in the aforementioned future paper. For the present study, we have used $n_{\mathrm{e}}=40, l_{\mathrm{p}}=4, l_{\mathrm{h}}=2$ and $g=1.1$. As shown in a future paper, these (optimal) choices allow for robust and reliable assimilation of AERONET data. Actually, an ensemble size of 40 is probably larger than necessary, $n_{\mathrm{e}}=20$ seems sufficient for our work.

A complete assimilation cycle consists of the forward simulation of the SPRINTARS ensemble for three hours (simulated world time) followed by a single execution of LETKF. The analysed aerosol fields then serve as initial conditions for the next forward simulation.

\subsection{The analyzed variable and the observations}

Allthough SPRINTARS (see also Sect. 3) simulates 22 subspecies of aerosol, we will summarize them into a fine (carbons and sulfate) and a coarse (sea salt and dust) mode for the purpose of assimilation (although SPRINTARS simulates a fine mode for seasalt and dust, we include them with the coarse mode. Figure 1 shows these fine modes do not affect overal seasalt and dust $\mathrm{AE}$ greatly). Thus, our state vector for the assimilation consists of fine and coarse mode mixing ratios at every grid-point, for all 20 vertical levels. After assimilation, mixing ratios for each sub-species are determined from their relative fractions before assimilation.

The observation operator $\mathbf{H}$, however, is calculated using the original sub-species mixing ratios. For each ensemble member, scattering properties per unit mass for both the fine and the coarse mode are calculated. An ensemble averaged scattering property $C_{k}^{\text {fin }}(\lambda)$ for e.g. the fine mode is defined as

$$
C^{\mathrm{fin}}(\lambda)=\left\langle\frac{\sum_{\mathrm{fine}} C^{\prime}(\lambda) x^{\prime}}{\sum_{\mathrm{fine}} x^{\prime}}\right\rangle
$$




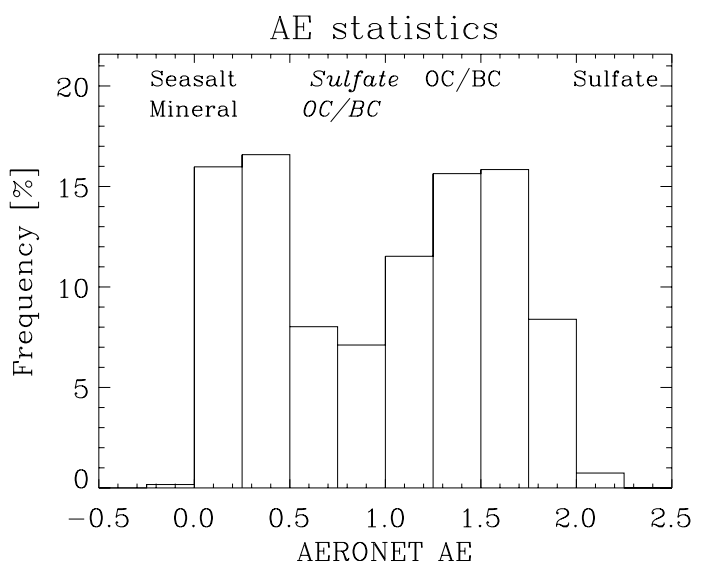

Fig. 1. Histogram of AE observed worldwide by AERONET for July 2005. Only observations with an estimated error smaller than 0.25 are shown. Also shown are current (regular font) and previous (italicized font) values of AE for the major SPRINTARS aerosol species (center of the text coincides with $\mathrm{AE}$ at $80 \%$ humidity).

where the accent denotes scattering properties and mixing ratios for each SPRINTARS sub-species and the brackets denote the ensemble average in every gridpoint.

This allows the following definition of the observation operation $\left(\mathbf{H} \cdot \mathbf{x}_{f}\right.$ in Eq. 1) for e.g. AOT,

$\tau(\lambda)=\sum_{k=1}^{k=20}\left(C_{k}^{\mathrm{fin}}(\lambda) x_{k}^{\mathrm{fin}}+C_{k}^{\mathrm{crs}}(\lambda) x_{k}^{\mathrm{crs}}\right) m_{k}^{\mathrm{atm}}$,

where $x_{k}$ is the aerosol fine or coarse mixing ratio for the $k$ th layer for a single ensemble member and $m^{\text {atm }}$ is the gaseous mass of said layer. Note that we sum over all $20 \sigma$-layers. For AOT, the observation operator is clearly linear. The Angström exponent AE is of-course a function of the wavelength dependence of AOT:

$\alpha=-\frac{\log \tau\left(\lambda_{2}\right) / \tau\left(\lambda_{1}\right)}{\log \lambda_{2} / \lambda_{1}}$,

which is clearly non-linear in the mixing ratios. Therefore, we linearize it around the ensemble mean.

There is quite some uncertainty about the exact growth curves of aerosol with humidity, and in particular the effects of aging and coagulation on those growth curves. The growth curves themselves affect the forward simulation by SPRINTARS (deposition speeds) and the assimilation by LETKF (scattering properties) and are therefore essential information. When the relative humidity exceeds $80 \%$, wetgrowth effects become very important. To limit errors in simulated observations, we do not assimilate observations when the column-averaged relative humidity (weighted by AOT per layer as calculated from the model) is over $80 \%$. Consequently, regions that routinely have high humidities will never benefit from assimilation and the analyzed fields in those regions will be similar to the forecast fields.

\section{SPRINTARS: global aerosol transport model}

SPRINTARS is a global transport model for aerosols (Takemura et al., 2000, 2002, 2005) built on top of the MIROC (Model for Interdisciplinary Research on Climate) AGCM (Numaguti et al., 1995). Four major groups of aerosol are represented by calculations in 22 different bins: sulfate (1 bin), carbons (7 species, each with their own bin), sea salt (4 size bins) and mineral (10 size bins). The model calculates emission, transport, gravitational settling and wet and dry deposition. We run SPRINTARS v. 3.54 at a resultion of t42 and $20 \sigma$-layers. This translates into a horizontal resolution of $2.8^{\circ}$ or about $312 \mathrm{~km}$ at the equator. The atmosphere has about 6 layers in the lowest $2.5 \mathrm{~km}$.

SPRINTARS was specifically designed for climate studies and hence allows feedback from the aerosol fields on the meteorological fields (both direct and indirect aerosol effects are accounted for, see Takemura et al., 2005). For assimilation purposes, this may not be the most practical setup (at least initially) as the aerosol fields will affect the meteorology. We try to temper this feedback by nudging the meteorological fields to NCEP reanalysis fields of temperature, horizontal windspeeds and specific humidity with a time-scale of half a day (a day for humidity).

The scattering properties of simulated aerosols are calculated differently from standard SPRINTARS (Takemura et al., 2002). First, the full particle size distribution is taken into account. (Original SPRINTARS uses scattering properties calculated at effective sizes only. For AOT this leads to relatively small differences, for Angström exponent the differences are significantly larger). Second, the widths of the size distribution for sulfate and carbons were modified. If we use the original width, AE for either sulfate or carbon individually is rather low $(<1)$ which precludes the possibility of high AE ( $>1.5$ ) as is often observed by AERONET (see Fig. 1). Therefore, we chose to use the widths as suggested by Omar et al. (2005) for the fine modes of his category 4 (industrial pollution) and category 2 (biomass burning) aerosol types.

The assimilation system requires an ensemble of SPRINTARS model calculations. The difference between the ensemble members should reflect our estimate of the model prediction error. In the current study, the ensemble members differ mainly in their emission scenarios. Furthermore, they will also differ in their initial conditions.

Since it is primarily uncertainty in emission inventories that is our concern, we create an ensemble by taking the standard aerosol emission inventories and modifying them for each ensemble member. Throughout the grid, each major species has its emission modified by the same random factor drawn from a log-normal distribution. The mean and spread of this distribution are both usually chosen to be 1 . In the present study, the sea-salt emission is not modified. Sulfate from $\mathrm{SO}_{2}$ emission (i.e. industrial pollution and ship exhausts) is modified but not sulfate from DMS or volcanic 
emission. The emissions of the seven sub-species of carbon aerosol are modified with the same factor. Similarly, the emissions of ten size bins of dust are modified with the same factor. As a result of these emission perturbations, the ratio of the standard deviation to the mean AOT for the individual major aerosol species has a value $\sim 0.6$ for carbon and sulfate, $\sim 0.6-2.4$ for dust (due to the different windfields of each member) and less than 0.2 for sea salt, in an ensemble run without assimilation.

Although we also vary initial conditions, this turned out to be relatively unimportant due to the short residence times of atmospheric aerosol. For the present study, we have randomly modified an initial condition (aerosol mixing ratios) determined from a year-long spin-up run. The initial conditions for the meteorological fields are derived from a spin-up run of SPRINTARS with unmodified emissions, which is itself initialized from the NCEP reanalysis.

\section{AERONET: AOT observations}

AERONET (http://aeronet.gsfc.nasa.gov/) is, to date, the most dedicated effort in establishing a global surface network with the purpose of observing the aerosol system. Since 1993, it has provided AOT and AE at various wavelengths, from 340 to $1640 \mathrm{~nm}$. Barring instrument malfunction, maintenance, clouds or low sun angles, measurements are made with a time sampling of $\sim 15 \mathrm{~min}$. Thanks to rigorous calibration, the instruments should be able to achieve an accuracy of $\epsilon_{o}=0.01-0.02$ (Eck et al., 1999). The AERONET website states that AOT for $\lambda>400 \mathrm{~nm}$, can be expected to have an error of 0.01. Comparison between instruments revealed errors of $\epsilon_{o}=0.015$ (Schmid et al., 1999). In recent years, the network has greatly expanded and up to 2009 included 446 stations (although not all were operated at the same time).

For our assimilation experiments, we will focus on July 2005. Of all AERONET data up to and including 2007, this is the month with the most observations. At that time 131 stations were operational (Fig. 2). From these stations we use quality-assured level $2 \mathrm{AOT}$ at $675 \mathrm{~nm}$ and $\mathrm{AE}$ based on AOT at 440 and $870 \mathrm{~nm}$. These wavelengths were chosen for their availability (e.g. not every station has a $500 \mathrm{~nm}$ channel) and relative accuracy (e.g. below $400 \mathrm{~nm}$, AOT errors estimates increase, retrieved AOT near $765 \mathrm{~nm}$ is insensitive to size distribution assumptions (Nakajima et al., 2007), AOT at $1020 \mathrm{~nm}$ is affected by water vapour). Scattering properties at 440 and $870 \mathrm{~nm}$ are also sufficiently different that $\mathrm{AE}$ can be expected to contribute independent information.

In preparing the AERONET data for assimilation, we will average them over $2 \mathrm{~h}$, centered on the latest SPRINTARS time-step. The error that will be attributed to this averaged observation is the (squared) sum of a representation error and an observational error $\epsilon^{2}=\epsilon_{r}^{2}+\epsilon_{o}^{2}$. Here the representation error is divided by the square root of the number of observa-

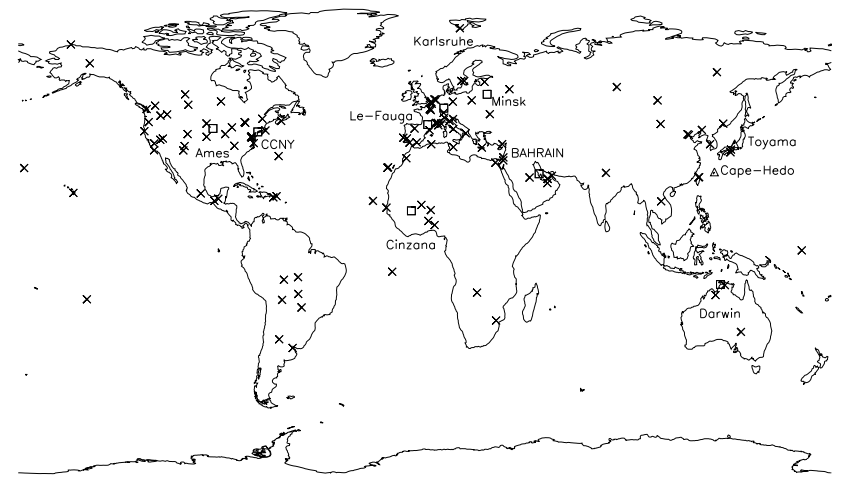

Fig. 2. Location of all surface sites used in this study. Crosses:AERONET sites used for assimilation; blocks: AERONET sites used for validation; triangle: SKYNET sites used for validation. The names of the validation sites are also indicated. Note that "Karlsruhe" had to be shifted to the North to prevent clutter.

tions in $2 \mathrm{~h}$ (essentially, we assume representation noise to be random and independent).

\subsection{AERONET AOT error analysis}

The observational error in AOT we estimate conservatively as $\epsilon_{o}=0.015$. Note that we also assume that this error is more or less constant during two hours.

To evalute the representational error, we look at the variability of AOT over short time ranges for both AERONET and SPRINTARS. We can estimate the AERONET AOT variability within half an hour or one hour of a central time (see Fig. 3) using $2 \mathrm{~h}$ time-intervals of uninterrupted observations for all AERONET sites in 2005 ( $3 \mathrm{~h}$ intervals would be more interesting but they occur only infrequently). These intervals were divided in a central $1 \mathrm{~h}$ interval and a remainder $1 \mathrm{~h}$ interval (consisting of two $30 \mathrm{~min}$. intervals). Relative differences with respect to the central interval mean were calculated. By taking results from all central intervals for one site, an estimate of the AOT variation within one hour at that site could be obtained (it is the standard deviation of relative differences). Likewise, an estimate of the AOT variation in the remainder $1 \mathrm{~h}$ interval was derived. In Fig. 3, these variations have been given a notional time differences of $15 \mathrm{~min}$ (central hour) and $45 \mathrm{~min}$ (remainder hour), which is the average time difference from the central time.

SPRINTARS AOT is only available with a sampling of $3 \mathrm{~h}$, so an analysis identical to the previous one is not possible. Instead we calculated the standard deviations of relative differences in subsequent SPRINTARS AOT values at the location of AERONET sites.

Figure 3 suggests that, at similar time scales, SPRINTARS variability is much less than that of AERONET. This difference in temporal variability is not surprising: SPRINTARS uses a timestep of $20 \mathrm{~min}$, at a relatively coarse spatial 


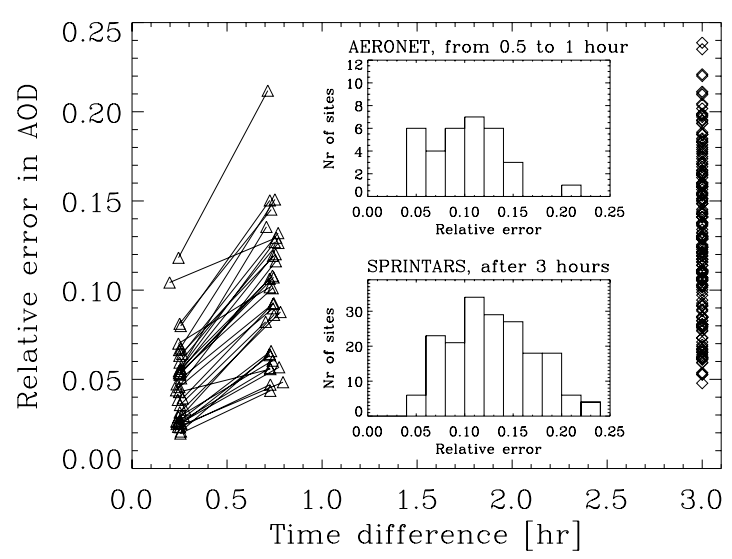

Fig. 3. Temporal variation of AERONET and SPRINTARS AOT at different time scales for individual sites. The triangles refer to variations in AERONET AOT. The diamonds refer to variations between 3-hourly SPRINTARS AOT.

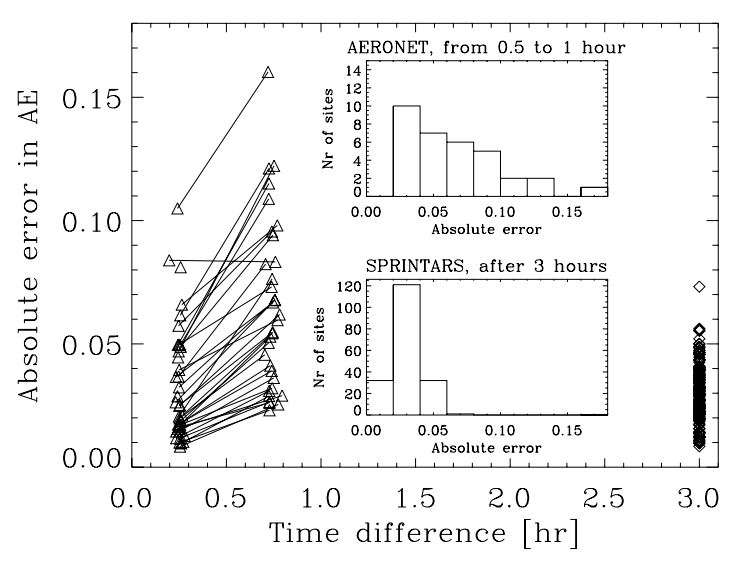

Fig. 4. Temporal variation of AERONET and SPRINTARS AE at different time scales for individual sites. The triangles refer to variations in AERONET AE. The diamonds refer to variations between 3-hourly SPRINTARS AE.

resolution. If we assume that SPRINTARS has any validity, then the lack of detail in the simulation is first of all the result of a (spatial and temporal) averaging operation. In that sense, we can interpret the variability in the AERONET observations as noise that would act as a representation error when comparing AERONET to SPRINTARS.

From Fig. 3 we conclude that the size of this representation error is, averaged over all sites, $5.5 \%$ in the central hour and $11 \%$ in the remainder hour. A convenient representation would be

$\epsilon_{r}=0.055 \tau \times\left(1+\operatorname{FLOOR}\left(\frac{\Delta t}{30 \mathrm{~min} .}\right)\right)$,

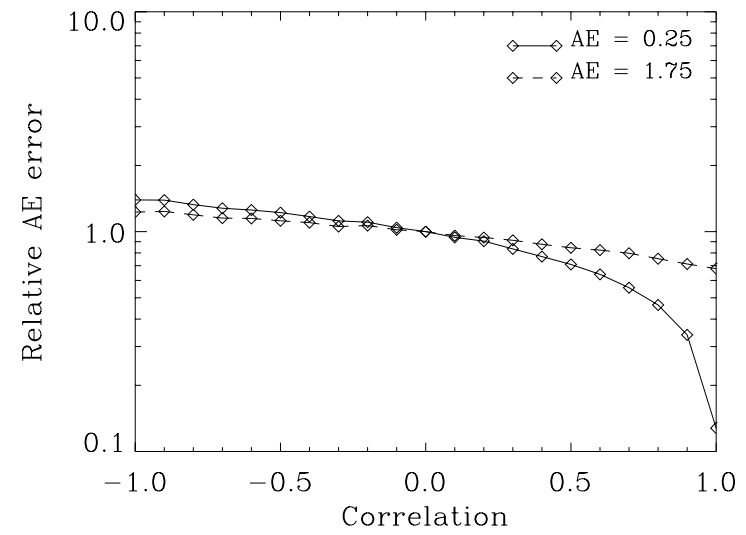

Fig. 5. The effect of correlations in AOT errors at 440 and $870 \mathrm{~nm}$ on the $\mathrm{AE}$ error. The error shown is relative to the absolute $\mathrm{AE}$ error for uncorrelated AOT errors. The absolute AOT errors at both wavelengths were assumed identical in magnitude.

where $\Delta t$ is the time separation (in minutes) between the time at assimilation and the relevant AERONET observation and FLOOR is the function that maps a value to its next lowest integer.

\subsection{AERONET AE error analysis}

A similar analysis of temporal variability can be made for $\mathrm{AE}$ and is shown in Fig. 4. We estimate the associated representation error to be

$\epsilon_{r}=0.025 \times\left(1+\operatorname{FLOOR}\left(\frac{\Delta t}{30 \mathrm{~min} .}\right)\right)$.

The observational error in AE can of course be estimated by propagating the observational errors in AOT at 440 and $870 \mathrm{~nm}$. Here we will assume that these errors are uncorrelated. Whether this is in fact true, is unknown. Neither a literature study, nor consulting with experts (O. Dubovik, A. Smirnov) yielded any information on this point. Sensitivity studies show that unless $\mathrm{AE}$ is small and the correlation is high (see Fig. 5), the effect of correlations in AOT on the error in $\mathrm{AE}$ is small.

\section{Validation of the assimilation}

We will now discuss results of the assimilation by comparing them to independent observations. For this purpose, eight AERONET sites were excluded in preparing observations for the assimilation. In addition SKYNET and MODIS observations will also be used for independent comparison. Table 1 defines the assimilation experiments that we performed. They differ in what observations are assimilated (AOT for $A 1$, AOT and $\mathrm{AE}$ for A2) and the global scaling factor (independent of the random perturbation, see Sect. 3) applied 
to the emission inventories ( 1 for $E 1$ and either 0.5 or 2 for $E 2)$. The experiments that we will discuss in some detail are $A 2 E 1, A 1 E 2$ and A2E2 (AlE1 is not discussed as it does not reveal anything new). Results will be compared to both independent observations and the control run Estd, which is the standard SPRINTARS simulation.

\subsection{Independent AERONET observations}

The AERONET sites excluded from the assimilated observations were chosen to have neigbouring AERONET sites in all four wind-directions, at a distance of least one grid cell. The exception is the Darwin site which only has Jabiru to the east. In Figs. 6 and 7, we show comparison between independent observations of AOT and $\mathrm{AE}$ and the results from assimilation experiments $A I E 2$ and $A 2 E 2$. The standard SPRINTARS simulation Estd is shown as well. Experiment $A 2 E 1$ looks similar to $A 2 E 2$.

Quite generally speaking, results for AOT and AE agree better with the observations because of the assimilation. Still many events of short duration are missed as well as some longer events. AE is only substantially affected when AOT is high, as may be expected (in that case, observational errors in the assimilated $\mathrm{AE}$ are small).

For the Ames site (central USA), we see that the standard AOT is significantly underestimated. Assimilation improves this but two multi-day events with poor AOT simulation still occur (10-12 July and 21-23 July). For the first event, a South-Easterly wind prevails, during which the Bondville site (located $475 \mathrm{~km}$ to the south-east of Ames) has almost no observations to be assimilated. For the second event, no apparent reason presented itself. Assimilation of AE does not appear to have much effect. In some cases, AE actually deteriorates. For the 5 July event this is likely due to low AOT.

For the CCNY site (east coast of USA), we see again an underestimation by the standard simulation, which is improved somewhat by the assimilation. Both the standard simulation and the assimilation overestimate AE. At least three such events (5 July and 9-10 July and 23 July) are characterized by low AOT $(\tau \leq 0.15)$.

At the Bahrain site (Kingdom of Bahrain, east of Saudi Arabia), we clearly see a strong positive impact of the asimilation on both AOT and AE. While AOT is overestimated in the standard simulation, $\mathrm{AE}$ is underestimated (too much coarse aerosol is in the air). The assimilation neatly corrects this. At Bahrain, in July 2005, the wind is mostly NorthWesterly but no nearby sites are located in that quadrant (e.g. SEDE_BOKER is some $1600 \mathrm{~km}$ away). We surmise that it is the downwind sites to the south of Bahrain that improve the simulation at Bahrain. Note also that although the $A l E 2$ experiment shows an AOT very similar to $A 2 E 2$, AE is overestimated.
Table 1. Assimilation experiments used in this paper.

\begin{tabular}{lccccc}
\hline id & assimilated & ensemble & \multicolumn{3}{c}{ scaling factor } \\
& observations & size & $f_{\text {carb }}$ & $f_{\text {sulf }}$ & $f_{\text {dust }}$ \\
\hline Estd & none & 1 & 1 & 1 & 1 \\
A1E1 & AOT & 40 & 1 & 1 & 1 \\
A2E1 & AOT \& AE & 40 & 1 & 1 & 1 \\
A1E2 & AOT & 40 & 0.5 & 2 & 0.5 \\
$A 2 E 2$ & AOT \& AE & 40 & 0.5 & 2 & 0.5 \\
\hline
\end{tabular}

Also at the Cinzana site (Mali, Western Africa), we see the positive impact of assimilation, but here the standard simulation tends to underestimate $\mathrm{AOT}$ and overestimate $\mathrm{AE}$ (too little dust in the air). The large discrepancies between the assimilated AOT and the observation in the first few days may be due to initial effects (the initial condition is also randomized in our ensemble), although no such thing is seen for the other sites. Note that assimilated AE shows large deviations from the observation at times of low AOT (e.g. 12 and 16 July). Again, the AlE2 experiment shows an AOT very similar to $A 2 E 2$, but $\mathrm{AE}$ is overestimated.

The European sites at Karlsruhe, Le_Fauga and Minsk will be collectively discussed. First of all, we see little difference between AOT and AE for both Estd and A2E2, as well as $A 2 E 1$ (note that $A 2 E 1$ is not shown, but $A 1 E 2$ is shown). All experiments agree reasonably well with the independent observations. This firstly suggest that the standard emission scenarios for Europe are quite acceptable. At the same time, assimilation is able to correct AOT when we assume incorrect emissions (A2E2). Le_Fauga shows two multiday events (9-11 July and 15-17 July) where the prevailing wind direction is Westerly and the assimilation is actually worse than the standard simulation. This is quite unusual and suggests model errors affecting the assimilation negatively. Since Le_Fauga is located just north of the Pyrénées mountains, it is interesting to note that wind direction and quality of the assimilation correlate. Northerly winds (10-13 July) yield good assimilation while a South-Westerly wind (1517 July) yields poor results.

The last site with independent observations to discuss is Darwin. This has only a single station nearby (Jabiru, $125 \mathrm{~km}$ to the East) but the wind is predominantly Easterly and the observations at both sites correlate well. Nevertheless, assimilated AOT and AE tend to be underestimated. It is also obvious that there is very little difference between the standard simulation and A2E2. According to the model, more than $50 \%$ of AOT comes from sea salt, that is not represented by an emission ensemble. More-over at the location of Jabiru, the model prediction error and the observation error in AOT are similar in size $(\sim 0.015)$, so the Jabiru observation should not be expected to have a large impact on the assimilation. 

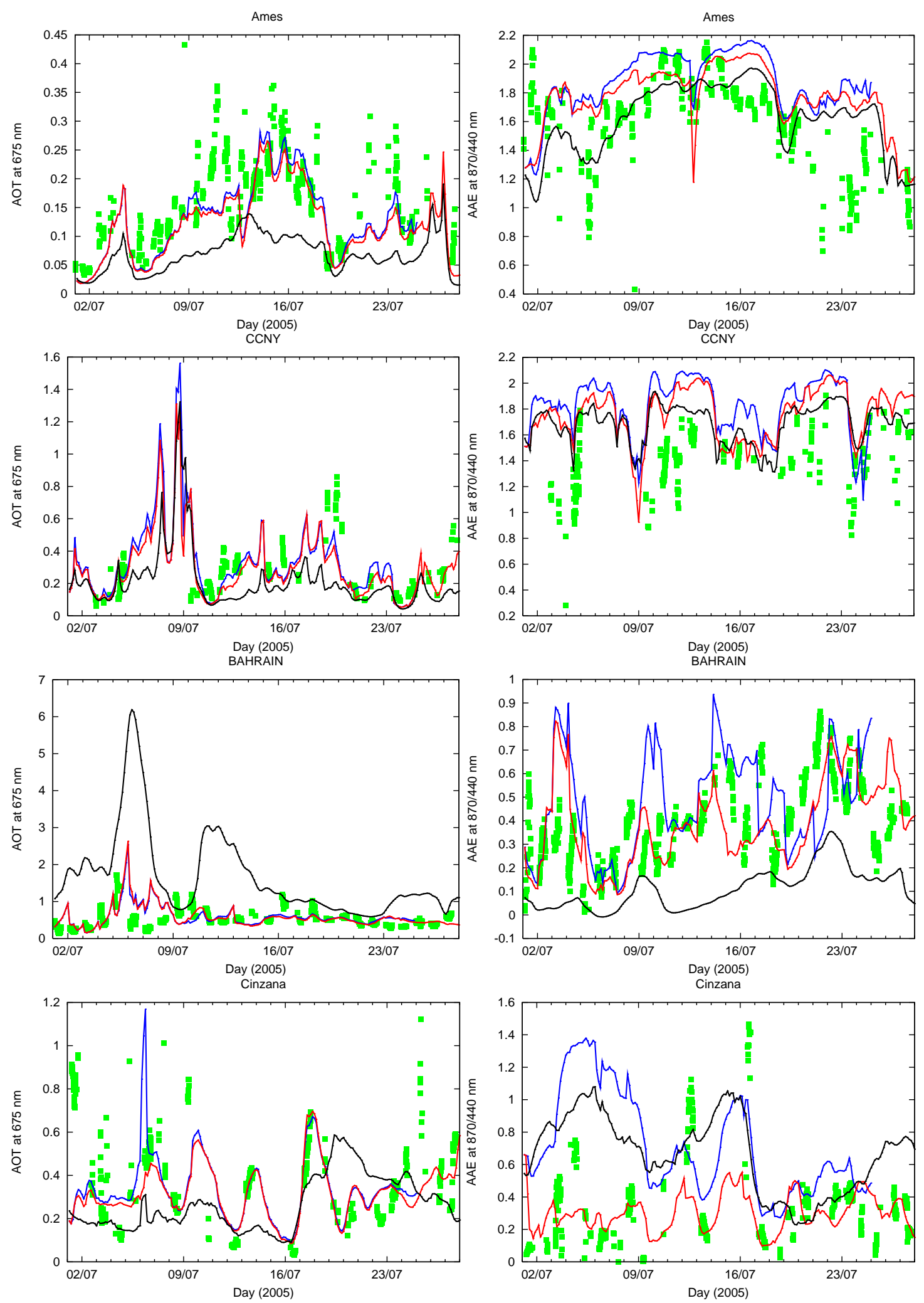

Fig. 6. AOT and AE at selected AERONET sites for both the Estd (black) simulation and the A1E2 (blue) and A2E2 (red) experiments. Also shown are actual observations (green squares). 

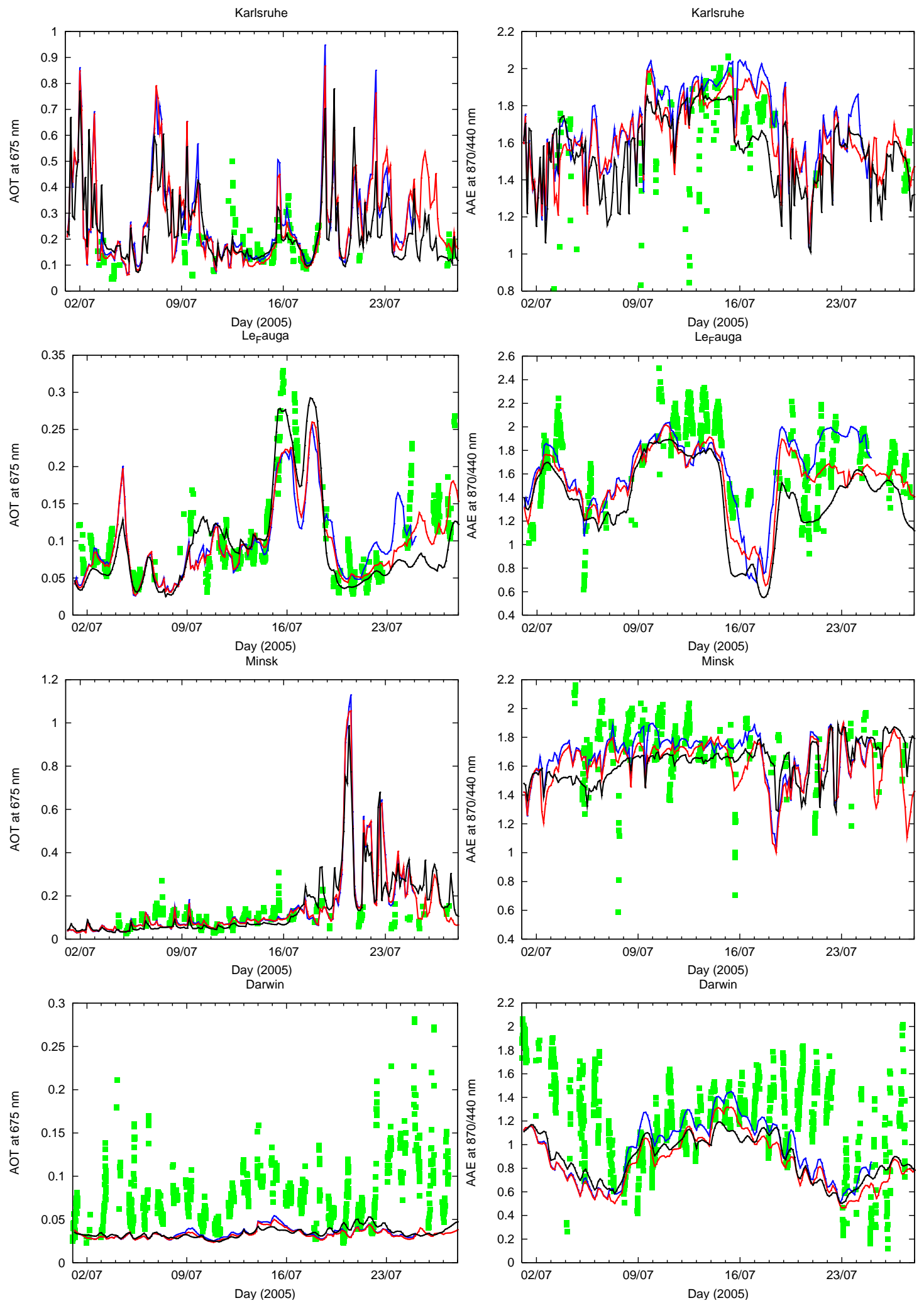

Fig. 7. AOT and AE at selected AERONET sites for both the Estd (black) simulation and the AlE2 (blue) and A2E2 (red) experiments. Also shown are actual observations (green squares). 

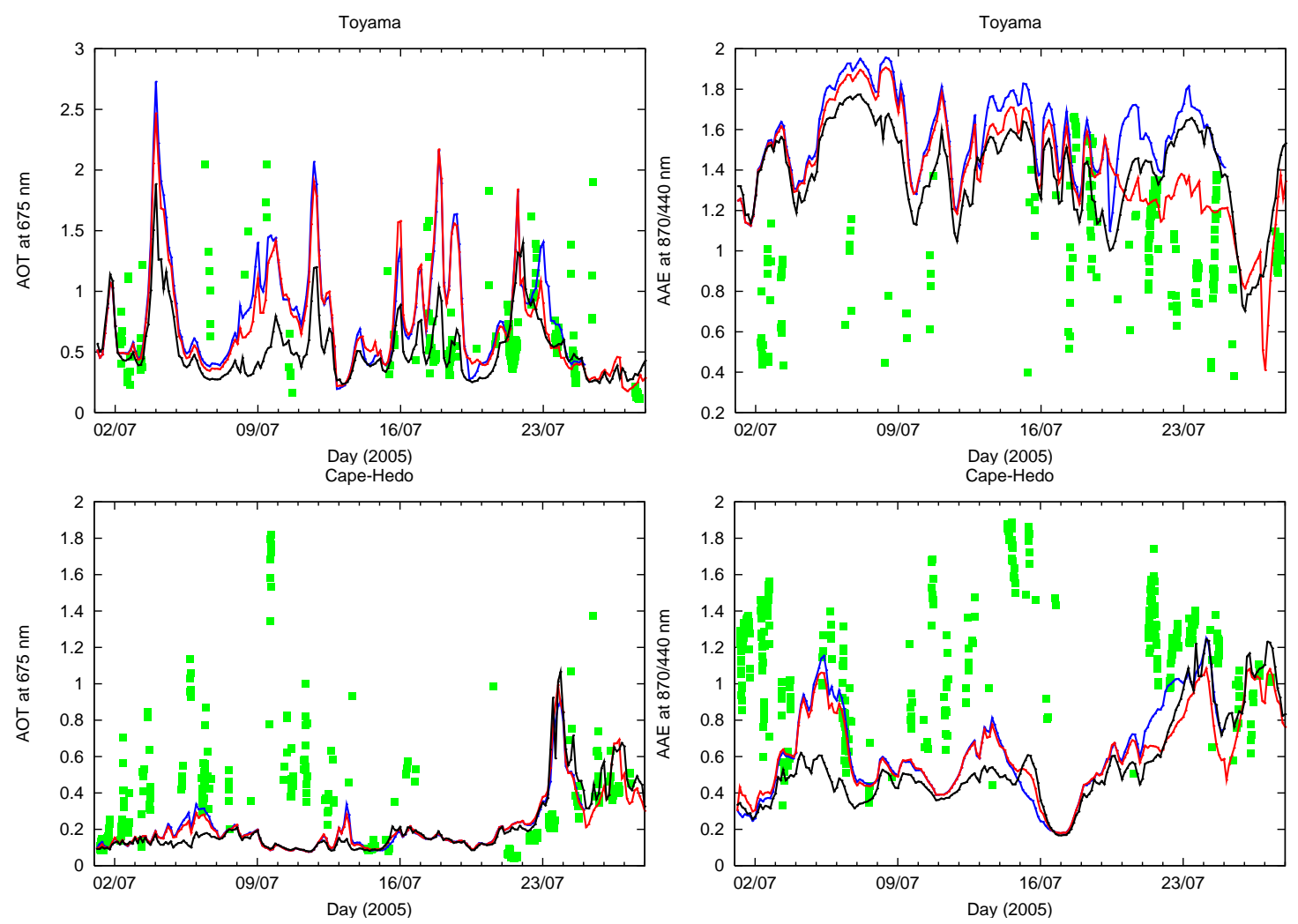

Fig. 8. AOT and AE at selected SKYNET sites for both the Estd (black) simulation and the A1E2 (blue) and A2E2 (red) experiments. Also shown are actual observations (green squares).

Finally we note that substantial differences between observed $\mathrm{AE}$ and the assimilation occur when either AOT also differs (Ames 4 and 21-24 July, CCNY 18-20 July, Cinzana 4 July, 24-25 July, Karlsruhe 12-13 July, Le_Fauga 1516 July, Minsk 7 July, 15 July) or observed AOT is very low (CCNY 2-4 July, 9-10 July, 21-23 July, Cinzana 12 July, 16 July, Le_Fauga 11-15 and 19-21 July, Minsk on most days). The first situation needs no corroboration, in the second situation observed AOT should be representative of the AOT of the assimilated observation and hence the error in assimilated AE. The Cinzana site is most instructive in this respect. Whenever AOT drops below 0.2, observed AE and the assimilation result can differ substantially.

\subsection{Independent SKYNET observations}

In Fig. 8 we show a comparison with SKYNET observations, which is a local South-East Asian network (http://atmos.cr. chiba-u.ac.jp/) rather similar to AERONET (see also Nakajima et al. (2007)) . Note that the number of AERONET sites in South-East Asia that can be used for assimilation is quite limited, so we don't expect a great impact from assimilation.

For instance at the Toyama (Japan) site, there is some difference between the standard simulation and $A 2 E 2$, but we can't really say that assimilation positively influences AOT in the first twenty days. However, the nearest AERONET sites (Osaka and Shirahama) have only few observations in the first half of the month. In the last ten days, they provide more observations and we see that the assimilation result for $A 2 E 2$ agrees better with the observations. More-over, it would seem that the SKYNET data for Toyama still suffer from some cloud contamination as can be seen in the relative high AOT in Fig. 8 and even more clearly in Fig. 9 where 2-h averages of AOT at Shirahama, Osaka and Toyama are plotted together.

The Cape_Hedo site (Okinawa, Japan) is more promising, with Tapei_CWB (700 km), Osaka \& Shirihama and Anmyon $(\sim 1100 \mathrm{~km})$ nearby. But also for this site, assimilation seems to have little impact. The first half of the month, the wind blows from the South-East and consequently sea salt dominates the standard simulation AOT at Cape_Hedo. The high AOT and AE actually observed are probably due to high sulfate loads, as confirmed by surface measurements (EA team, 2005). They likely result from the volcanic eruptions by Anatahan (M. Ruminski, personal communication, 2009). A movie can be seen at http://so2.umbc.edu/omi/movies/wpac_ omso2_1jan-30sep05.mov that clearly shows the $\mathrm{SO}_{2}$ plume from Anatahan, as detected by OMI (Ozone Monitoring 
Instrument), sweeping over Cape_Hedo in July 2005. In the second half of the month, the winds shift and now blow industrial pollution from the Asian mainland over Cape_Hedo. Consequently, the assimilation seems to yield better results.

\subsection{Independent MODIS observations}

Finally, we compare our assimilation experiment $A 2 E 1$ to MODIS Aqua observations (coll. 5) of AOT at $550 \mathrm{~nm}$. For the independent AERONET data, we found only small differences between experiments $A 2 E 1$ and $A 2 E 2$. But now that we turn to satellite observations that cover a large area, considerable parts of which may not be sampled by the AERONET sites for assimilation, it seems better to use an emission ensemble centered around the standard SPRINTARS emission scenarios.

Of course, direct comparison between AOT for the simulation and the MODIS observations will not be straightforward. First of all, there is a large discrepancy in the spatial resolution of the model $\left(2.8^{\circ}\right)$ and the observations $(10 \mathrm{~km})$. We have resampled the MODIS observations to $0.5^{\circ}$ by $0.5^{\circ}$ but this does not improve the discretized model calculation. Next, there is a difference in temporal sampling. The global model AOT is known at three hour intervals, while the observations are taken at various times depending on the geographic location. We have averaged model AOT over the range of relevant MODIS observation times. Thirdly, satellite observations of AOT over land are notoriously difficult due to errors in assumed surface albedo and assumed aerosol type. Fourthly, MODIS observations are not always available due to e.g. cloudiness. When they are available, they may be contaminated with cloud signals. Finally, model and MODIS AOT are calculated for slightly different wavelengths (500 vs. $550 \mathrm{~nm}$ ). Due to these reasons, we can only hope to compare general patterns in AOT in the following paragraphs.

We have selected three scenes for comparison based on the following criteria. Since the AERONET network should sample these scenes sufficiently, we are limited to Northen America, Northern Africa and Europe. Also, there should be a significant difference between the standard simulation and the assimilation experiment $A 2 E 1$. This led us to select three particular dates.

In Fig. 10, we show Europe and Northern Africa on 13 July 2005. In agreement with the MODIS observations are the following. The assimilated AOT shows a strong reduction of the extensive dust storm over Sudan, Ethiopia and the Arabian peninsula. Likewise, the dust storm over Algeria is not as pronounced. The pollution over Northern France and the low countries has increased in the assimilated AOT. However, neither standard nor assimilated AOT agree with the MODIS observations of dust storms on the African west coast or in Niger or the pollution in Spain. A couple of interesting features, like the changes in pollution over Italy, Romania and the Black sea can not be verified due to cloudiness in the satellite observations.

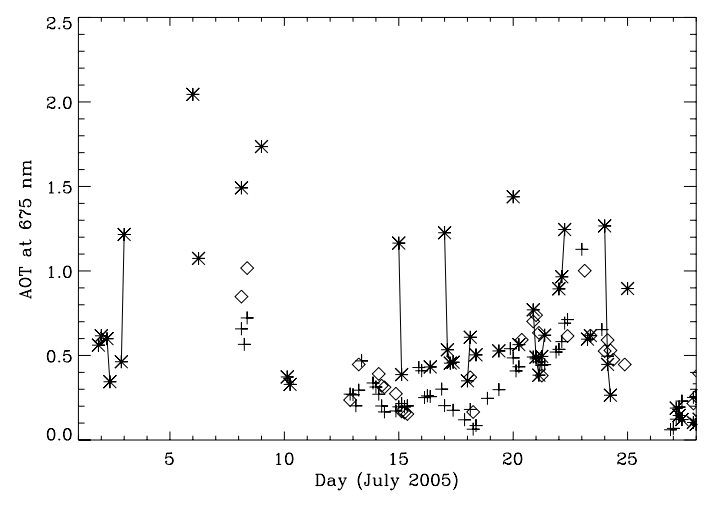

Fig. 9. Observed 2-h averaged AOT for Toyama (asterisks), Osaka (diamonds) and Shirahama (plusses). Consecutive Toyama data are connected with lines to bring out the sudden AOT changes, likely due to cloud contamination.

In Fig. 11, we show Northern America on 14 July 2005. In agreement with the MODIS observations are the following. The assimilated AOT is significantly increased in central East America and there is more aerosol in Southern California and Baja California (Mexico). In addition assimilated AOT is increased west of Hudson bay, something the MODIS observations seems to confirm although many observations are absent. Neither Estd nor A2E1 predicts the aerosol seen by MODIS either South of Hudson bay or in North West Canada.

Finally, we again turn to Europe on 26 July 2005 in Fig. 12. Assimilated AOT due to dust and pollution is elevated over the standard AOT, in North Africa, the Mediterranean and Northern Italy as well as Central Europe, as confirmed by MODIS. Regretabbly the higher assimilated AOT over North West Europe can not be validated due to cloudiness. Neither standard nor assimilated AOT shows the pollution east of the Caspian sea.

Clearly, assimilated AOT is often in better agreement with the observations than the standard AOT. If there are insufficient AERONET sites, then the assimilation often fails to improve AOT. Finally, we point out that even when MODIS observes clouds, and hence cannot be used to validate assimilated AOT, assimilated AOT may still be improved due to unobscured observations assimilated at earlier times.

\section{Summary and conclusions}

We have developed, implemented and tested an assimilation system for a global aerosol transport model. Our aerosol model SPRINTARS calculates the emission, transport and removal (due to gravitational settling, wet and dry deposition) of four basic aerosol species (carbons, sulfate, sea salt and dust). The assimilation is performed by a Local Ensemble Transform Kalman filter. In this paper the ensemble of 

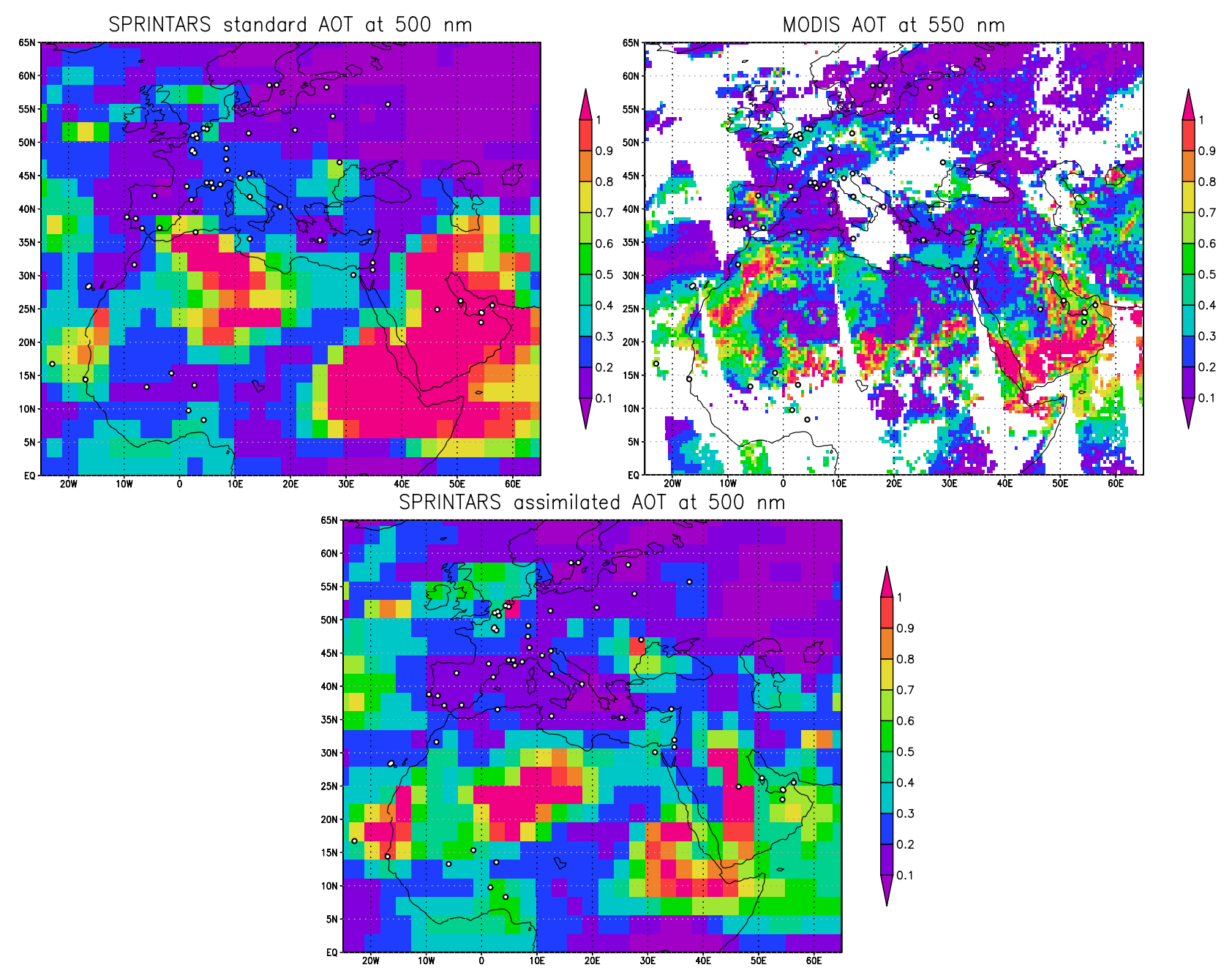

Fig. 10. AOT over Europe and Northern Africa on 13 July 2005 (09:00-14:00 GMT). Top left panel shows the standard SPRINTARS simulation, top right panel shows MODIS Aqua observations and bottom panel shows SPRINTARS assimilation.

model simulations is constructed by modifying the standard emission scenarios for SPRINTARS, in particular those for sulfate, carbons and desert dust.

Using an ensemble of model simulations is a computationally efficient way to represent spatially and temporally varying model covariant information, that is used to spread the information from localized observations throughout the model grid. Other assimilation schemes (Optimal Interpolation, 3D-var, 4D-var) have to employ a-priori assumed model covariances (often constant in space and time), that are decoupled from the model calculations. In addition, our analyzed variables are the mixing ratios of the aerosol fine and coarse mode in an atmospheric profile. Most aerosol assimilation schemes analyze AOT, and require extra assumptions on how this translates into profiles of mixing ratios.

In this paper, we assimilate quality-assured level 2 AOT $(675 \mathrm{~nm})$ and AE $(870$ vs. $440 \mathrm{~nm})$ from AERONET sites.
These observations were averaged over two hours to increase their representativeness for a model simulation run at $\mathrm{t} 42$ with a 20 min time-step. Particular attention was given to error estimates of the assimilated observations, which consists of independent contributions of an observational error and a representation error (high frequency noise due to small scale aerosol physics).

In a future paper, we discuss sensitivity studies in which we varied several numerical parameters and assumptions required by the ensemble Kalman filter. In this paper, all experiments were conducted for a 40-member ensemble but a 20-member ensemble seems to yield similar results.

In the current paper, however, we only discuss results for 4 assimilation experiments where we varied some basic assumptions about the emission scenarios (in particular: a scaling factor) and the type of assimilated observations (either AOT only or both AOT and AE). Simulated fields of AOT 

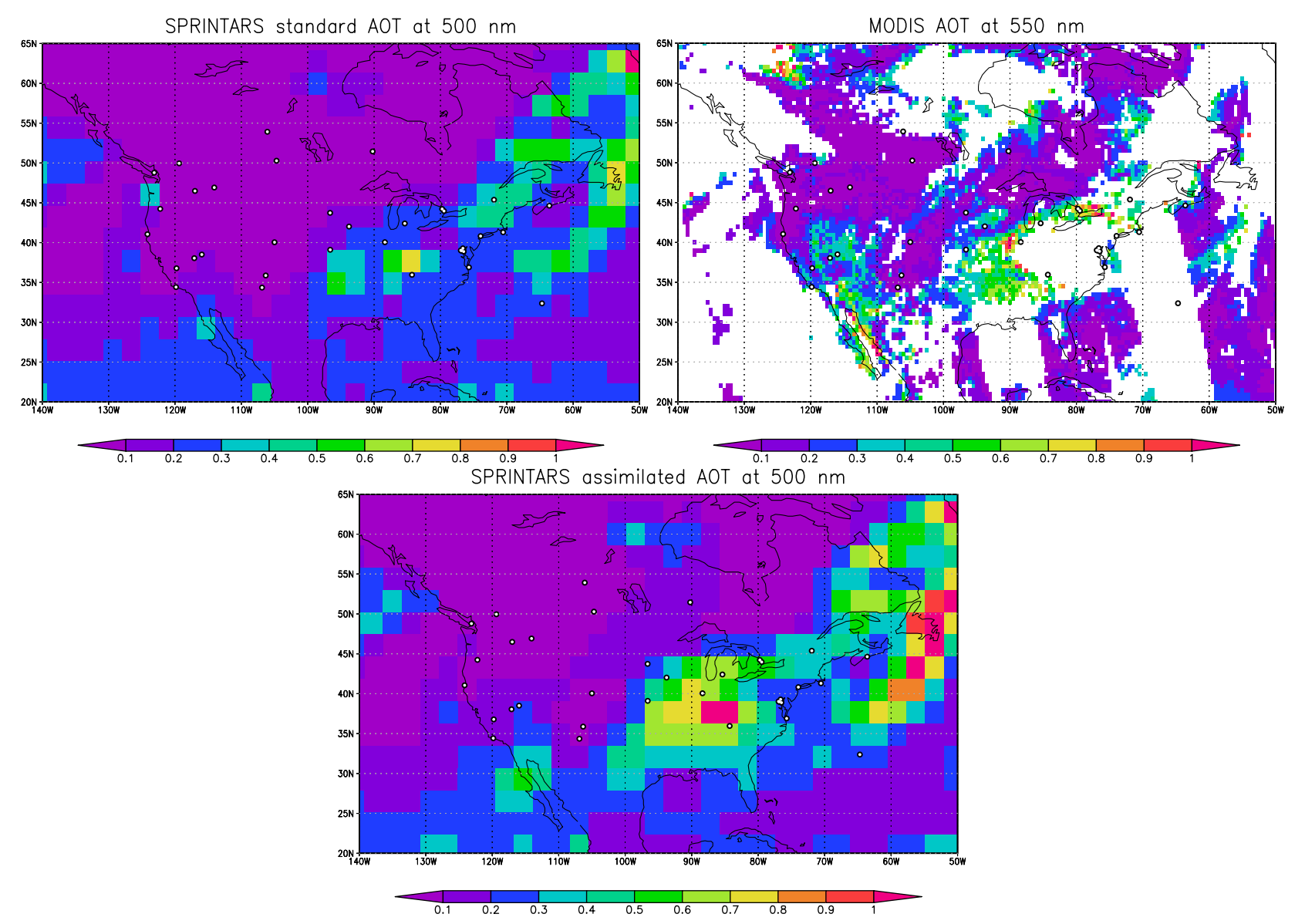

Fig. 11. AOT over Northern America on 14 July 2005 (16:00-2200 GMT). Top left panel shows the standard SPRINTARS simulation, top right panel shows MODIS Aqua observations and bottom panel shows SPRINTARS assimilation.

and AE from these experiments are compared to both a standard simulation with SPRINTARS (no assimilation) and independent observations at various geographic locations. In particular, we excluded 8 AERONET sites from contributing observations to the assimilation and later used them for validation. In addition, SKYNET observations (South-East Asia) and MODIS Aqua observations of Northern America, Europe and Northern Africa were also used for validation.

The comparison with independent AERONET observations is important as they are the most reliable and accurate data set used for validation. However, the validation sites were chosen to be in fairly close proximity to other sites (more than 1 but less than 3 grid cells distance) and usually were "surrounded" in all four wind directions by AERONET sites that contributed observations to the assimilation.

Results show that the assimilation can substantially improves modelled AOT and sometimes AE. This is particularly obvious for the North American (Ames, CCNY), African (Cinzana) and Arabian (BAHRAIN) sites, where the standard simulation diverges strongly from the observation. However, our experiments with various emission scenarios show that also for European sites, where the standard simulation is more acceptable, the assimilation improves the AOT. Assimilating AE leads to a substantial improvement of modelled AE for Cinzana and BAHRAIN. However, the NorthAmerican and European sites seem not to benefit much from the additional information present in AE. One reason is likely the large errors in AE observations due to low AOT. From the Cinzana and BHARAIN results we surmise that AOT needs to be at least $\sim 0.4$ if $\mathrm{AE}$ is to have any positive effect. However, the fact that $\mathrm{AE}$ observations are useful in low $\mathrm{AE}$ cases but less so in high AE cases, may also be due to our definition of fine mode aerosol. This fine mode consists of both sulfate and carbon aerosols that have different AE contributions (see Fig. 1).

The comparison with SKYNET observations are interesting as there are not many AERONET sites in South-East Asia and we wanted to use them all for assimilation. Unfortunately, in the period we considered (July 2005) only two SKYNET stations provided sufficient observations. For the Cape-Hedo site (Japan), a nearby erupting volcanoe (Anatahan) introduced large quantities of $\mathrm{SO}_{2}$ that our emission 

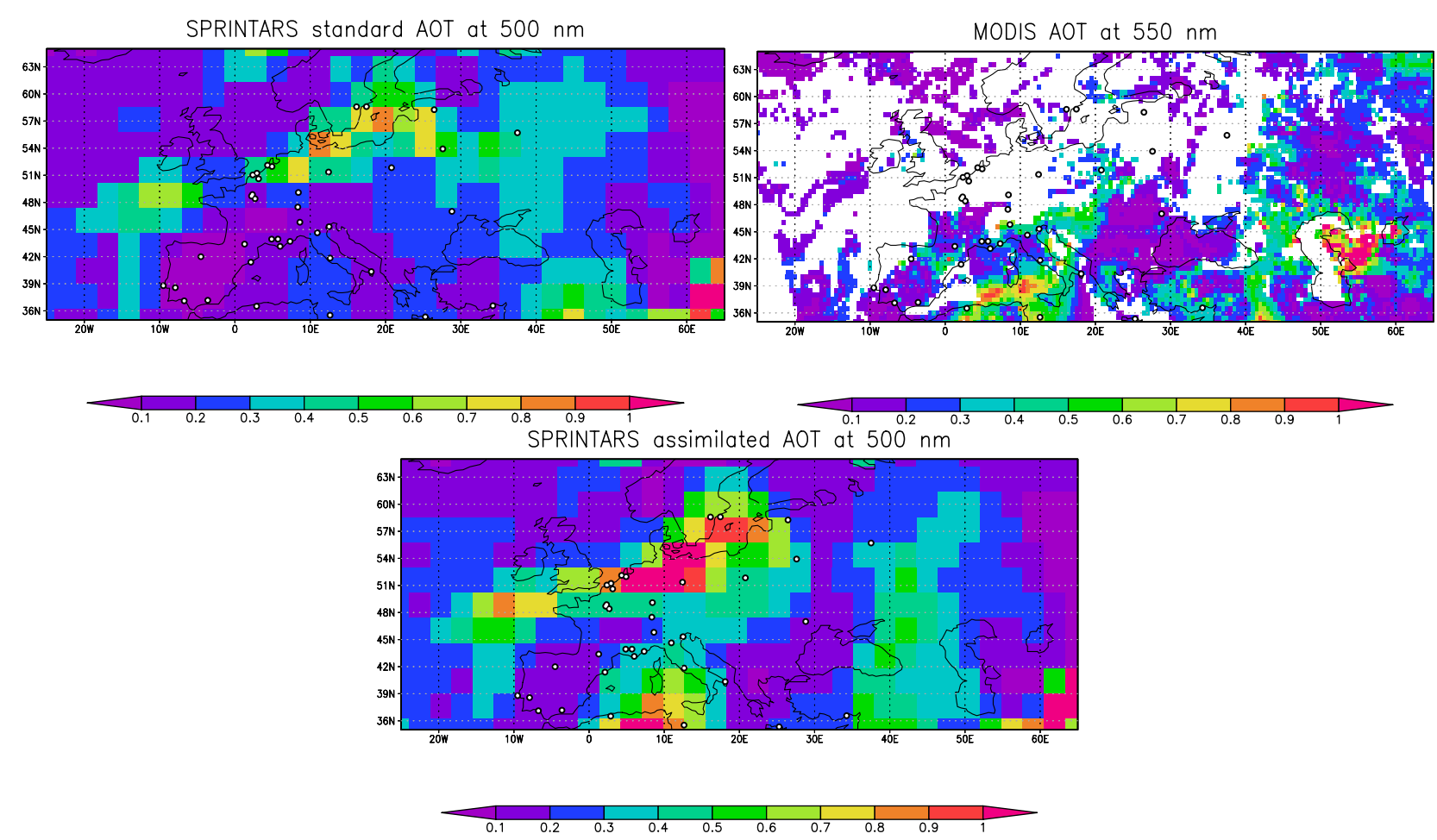

Fig. 12. AOT over Europe on 26 July 2005 (09:00-14:00 GMT). Top left panel shows the standard SPRINTARS simulation, top right panel shows MODIS Aqua observations and bottom panel shows SPRINTARS assimilation.

inventories did not include. Whether it is possible to represent both quiet and active phases of volcanoes in our emission ensemble remains a topic for further study. For the Toyama site (Japan), the nearby AERONET sites that supplied observations to the assimilation experienced a lot of data loss due to cloudiness. In addition, the Toyama SKYNET data itself seem not entirely free of cloud contamination. Nevertheless, the comparison for the second half July 2005 shows improvement in AOT due to assimilation.

Finally, we compared assimilation results with MODIS Aqua data. This allows us to study the effect of assimilation on the spatial distribution of aerosol. For three separate days in July 2005, comparison was made among standard and assimilated AOT as well as MODIS AOT for either NorthAmerica or Europe and North-Africa. Results show the assimilation correctly adjusts AOT to either higher of lower levels. However, we also found several cases of pollution or dust storms that were present in the MODIS data but not in the standard simulation or the assimilation. This points to remaining issues with the original emission inventories, in particular the spatial distribution of sources.

Concluding, we feel that the assimilation system was successfully validated against independent observations. On a global scale, assimilating AOT yielded better results than the standard simulation. The usefullness of assimilating AE is for the moment, however, limited to high AOT (>0.4) and low AE cases. To improve this one could assume smaller AERONET AOT errors (our choice was quite conservative) and/or use three aerosol modes to analyze (e.g. sulfate, carbon and coarse). While validating our assimilation results, it became apparent that the standard emission scenarios limit the usefullness of assimilation since the emission ensemble is a random modification of the standard emission. Hence where there is no emission in the standard model, there will be no emission in the ensemble.

In the current paper, only AERONET data were assimilated but this is no limitation of the system. At the moment, the assimilation system supports AOT data from the MODIS satellite sensor as well as AOT and AE from two local South-East Asian ground networks (CSHNET and SKYNET). Also attenuated backscatter from ground-based LIDARs employed by the Asian Dust network can be assimilated.

Future developments of the assimilation system will include a 4D-LETKF version which will consider the evolution of the ensemble during an arbitrary time-window, and an extension of the definition of the ensemble (e.g. variation in deposition speeds). This work was done as preparation for the GOSAT-CAI imager onboard GOSAT. 
Acknowledgements. We thank the relevant PIs and their staff for establishing and maintaining the AERONET sites used in this investigation. The NASA MODIS team is acknowledged for preparing and making available MODIS observations. T. Takamura and K. Aoki are thanked for the SKYNET data they provided. We also acknowledge the useful comments by two anonymous reviewers that helped improve this paper. The first author, N. A. J. Schutgens furthermore acknowledges the help from M. Mukai and D. Goto in learning how to use SPRINTARS. Part of this research was supported by funds from MOE/GOSAT, MOE/GER fund B-083, JST/CREST, JAXA/EarthCARE, MEXT/VL for climate diagnostics, and MEXT/Innovative Program of Climate Change Projection.

Edited by: J. Quaas

\section{References}

Benedetti, A., Morcrette, J.-J., Boucher, O., Dethof, A., Engelen, R., Fisher, M., Flentje, H., Huneeus, N., Jones, L., Kaiser, J., Kinne, S., Mangold, A., Razinger, M., Simmons, A., and Suttie, M.: Aerosol analysis and forecast in the European Centre for Medium-Range Weather Forecasts Integrated Forecast System: 2. Data assimilation, J. Geophys. Res., 114, D13205, doi: 10.1029/2008JD011115, 2009.

Bouttier, F. and Courtier, P.: Data assimilation concepts and methods, ECMWF training course notes, internet document, http://www.ecmwf.int/newsevents/training/ rcourse_notes/DATA_ASSIMILATION/ASSIM_CONCEPTS/ Assim_concepts21.html, last accessed: 2006, 1999.

Collins, W., Rasch, P., Eaton, B., Khattatov, B., and Lamarque, J.F.: Simulating aerosols using a chemical transport model with assimilation of satellite aerosol retrievals: methodology for INDOEX, J. Geophys. Res., 106, 7313-7336, 2001.

Dubovik, O., Lapyonok, T., Kaufman, Y. J., Chin, M., Ginoux, P., Kahn, R. A., and Sinyuk, A.: Retrieving global aerosol sources from satellites using inverse modeling, Atmos. Chem. Phys., 8, 209-250, 2008,

http://www.atmos-chem-phys.net/8/209/2008/.

EA team: Data report on the acid deposition in the East Asian region, Tech. rep., Network center for EANET, http://www.eanet. cc/, last accessed: 2009, 2005.

Eck, T., Holben, B., Reid, J., Dubovik, O., Smirnov, A., O’Neill, N., Slutsker, I., and Kinne, S.: Wavelength dependence of the optical depths of biomass burning, urban, and desert dust aerosols, J. Geophys. Res., 104, 31333-31349, 1999.

Evensen, G.: Sequential data assimilation with a nonlinear quasigeostrophic model using Monte Carlo methods to forecast error statistics, J. Geophys. Res., 99, 10143-10162, 1994.

Generoso, S., Bréon, F., Chevallier, F., Balkanski, Y., Schulz, M., and Bey, I.: Assimilation of POLDER aerosol optical thickness into the LMDz-INCA model: implications for the artic aerosol burden, J. Geophys. Res., 112, D02311, doi:10.1029/ 2005JD006954, 2007.

Ghan, S. and Schwartz, S.: Aerosol properties and processes, BAMS, 88, 1059-1083, doi:10.1175/BAMS-88-7-1059, 2007.

Henzing, B.: Aerosol modelling: spatial distribution and effects on radiation, Ph.D. thesis, Technical University Eindhoven, the Netherlands, 2005.
Houtekamer, P. and Mitchell, H.: Data assimilation using an ensemble Kalman filter technique, Mon. Weather Rev., 126, 796-811, 1998.

Hunt, B., Kostelich, E., and Szunyogh, I.: Efficient data assimilation for spatiotemporal chaos: a Local Ensemble Transfom Kalman Filter, Physica D, 230, 112-126, 2007.

Kalnay, E., Miyoshi, T., Yang, S., and Ballabrera-Poy, J.: 4D-Var or ensemble Kalman filter?, Tellus, 59A, 758-773, 2007.

Lin, C., Wang, Z., and Zhu, J.: An Ensemble Kalman Filter for severe dust storm data assimilation over China, Atmos. Chem. Phys., 8, 2975-2983, 2008,

http://www.atmos-chem-phys.net/8/2975/2008/.

Miyoshi, T. and Yamane, S.: Local Ensemble Transform Kalman filtering with an AGCM at a T159/L48 resolution, Mon. Weather Rev., 135, 3841-3861, 2007.

Nakajima, T., Yoon, S.-C., Ramanathan, V., Shi, G.-Y., Takemura, T., Higurashi, A., Takamura, T., Aoki, K., Sohn, B.-J., Kim, S.-W., Tsuruta, H., Sugimoto, N., Shimizu, A., Tanimoto, H., Sawa, Y., Lin, N.-H., Lee, C.-T., Goto, D., and Schutgens, N.: Overview of the Atmospheric Brown Cloud East Asian Regional Experiment 2005 and a study of the aerosol direct radiative forcing in east Asia, J. Geophys. Res., 112, D24S91, doi: 10.1029/2007JD009009, 2007.

Niu, T., Gong, S. L., Zhu, G. F., Liu, H. L., Hu, X. Q., Zhou, C. H., and Wang, Y. Q.: Data assimilation of dust aerosol observations for the CUACE/dust forecasting system, Atmos. Chem. Phys., 8, 3473-3482, 2008, http://www.atmos-chem-phys.net/8/3473/2008/.

Numaguti, A., Takahashi, M., Nakajima, T., and Sumi, A.: Development of an atmospheric general circulation model, in: Climate System Dynamics and Modelling, edited by: Matsuno, T., 1-27, CCSR, U. Tokyo, 1995.

Omar, A., Won, J.-G., Winkler, D., Yoon, S., Dubovik, O., and McCormick, M.: Development of global aerosol models using cluster analysis of Aerosol Robotic Network (AERONET) measurements, J. Geophys. Res., 110, D10S14, doi:10.1029/ 2004JD004874, 2005.

Rodgers, C.: Inverse methods for atmospheric sounding: theory and practice, vol. 2 of Atmospheric, Oceanic and planetary physics, World Scientific, 2000.

Schmid, B., Michalsky, J., Halthore, R., Beauharnois, M., Harrison, L., Livingston, J., Russel, P., Holben, B., Eck, T., and Smirnov, A.: Comparison of aerosol optical depth from four solar radiometers during the fall 1997 ARM intensive observation period, Geophys. Res. Lett., 26, 2725-2728, 1999.

Sekiyama, T. T., Tanaka, T. Y., Shimizu, A., and Miyoshi, T.: Data assimilation of CALIPSO aerosol observations, Atmos. Chem. Phys., 10, 39-49, 2010, http://www.atmos-chem-phys.net/10/39/2010/.

Szunyogh, I., Kostelich, E., Gyarmati, G., Kalnay, E., Hunt, B., Ott, E., Satterfield, E., and Yorke, J.: A local ensemble transform Kalman filter data assimilation system for the NCEP global model, Tellus, 60A, 113-130, doi:10.1111/j.1600-0870.2007. 00274.x, 2008.

Takemura, T., Okamoto, H., Maruyama, Y., Numaguti, A., Higurashi, A., and Nakajima, T.: Global three-dimensional simulation of aerosol optical thickness distribution of various origins, J. Geophys. Res., 105, 17853-17873, 2000.

Takemura, T., Nakajima, T., Dubovik, O., Holben, B., and Kinne, 
S.: Single-scattering albedo and radiative forcing of various aerosol species with a global three-dimensional model, J. Clim., 15, 333-352, 2002.

Takemura, T., Nozawa, T., Emori, S., Nakajima, T., and Nakajima, T.: Simulation of climate response to aerosol direct and indirect effects with aerosol transport-radiation model, J. Geophys. Res., 110, D02202, doi:10.1029/2004JD005029, 2005.

Textor, C., Schulz, M., Guibert, S., Kinne, S., Balkanski, Y., Bauer, S., Berntsen, T., Berglen, T., Boucher, O., Chin, M., Dentener, F., Diehl, T., Easter, R., Feichter, H., Fillmore, D., Ghan, S., Ginoux, P., Gong, S., Grini, A., Hendricks, J., Horowitz, L., Huang, P., Isaksen, I., Iversen, I., Kloster, S., Koch, D., Kirkevg, A., Kristjansson, J. E., Krol, M., Lauer, A., Lamarque, J. F., Liu, X., Montanaro, V., Myhre, G., Penner, J., Pitari, G., Reddy, S., Seland, Ø., Stier, P., Takemura, T., and Tie, X.: Analysis and quantification of the diversities of aerosol life cycles within AeroCom, Atmos. Chem. Phys., 6, 1777-1813, 2006, http://www.atmos-chem-phys.net/6/1777/2006/.

Textor, C., Schulz, M., Guibert, S., Kinne, S., Balkanski, Y., Bauer, S., Berntsen, T., Berglen, T., Boucher, O., Chin, M., Dentener, F., Diehl, T., Feichter, J., Fillmore, D., Ginoux, P., Gong, S., Grini, A., Hendricks, J., Horowitz, L., Huang, P., Isaksen, I. S. A., Iversen, T., Kloster, S., Koch, D., Kirkevåg, A., Kristjansson, J. E., Krol, M., Lauer, A., Lamarque, J. F., Liu, X., Montanaro, V., Myhre, G., Penner, J. E., Pitari, G., Reddy, M. S., Seland, Ø., Stier, P., Takemura, T., and Tie, X.: The effect of harmonized emissions on aerosol properties in global models - an AeroCom experiment, Atmos. Chem. Phys., 7, 4489-4501, 2007, http://www.atmos-chem-phys.net/7/4489/2007/.
Tombette, M., Mallet, V., and Sportisse, B.: $\mathrm{PM}_{10}$ data assimilation over Europe with the optimal interpolation method, Atmos. Chem. Phys., 9, 57-70, 2009, http://www.atmos-chem-phys.net/9/57/2009/.

Whitaker, J. and Hamill, T.: Ensemble data assimillation without perturbed observations, Mon. Weather Rev., 130, 1913-1924, 2002.

Yu, H., Dickinson, R., Chin, M., Kaufman, Y., Holben, B., Geogdzhayev, I., and Mishchenko, M.: Annual cycle of global distributions of aerosol optical depth from integration of MODIS retrievals and GOCART model simulations, J. Geophys. Res., 108(D3), 4128, doi:10.1029/2002JD002717, 2003.

Yumimoto, K., Uno, I., Sugimoto, N., Shimizu, A., Liu, Z., and Winker, D. M.: Adjoint inversion modeling of Asian dust emission using lidar observations, Atmos. Chem. Phys., 8, 28692884, 2008, http://www.atmos-chem-phys.net/8/2869/2008/.

Zhang, J., Reid, J. S.Westphal, D., Baker, N., and Hyer, E.: A system for operational aerosol optical depth data assimilation over global oceans, J. Geophys. Res., 113, D22207, doi: 1029/2007JD009065, 2008. 